\title{
The effect of proficiency pairings on EFL students' writing ability in genre-based approach context
}

\author{
Ani Susanti ${ }^{1}$, Utami Widiati², Bambang Yudi Cahyono ${ }^{3}$ \\ ${ }^{1}$ Department of English Education, Universitas Ahmad Dahlan, Indonesia \\ ${ }^{1,2,3}$ Graduate Program in English Language Teaching, Universitas Negeri Malang, Indonesia
}

\section{Article Info \\ Article history: \\ Received Dec 10, 2019 \\ Revised Feb 14, 2020 \\ Accepted Feb 24, 2020}

\section{Keywords:}

Collaborative writing tasks EFL students' writing ability Proficiency pairings

\begin{abstract}
This study aimed to know if students who work in heterogeneous (HET) pairs have significantly better writing ability than those who experience working in homogenous (HOM) pairs. This study involved two intact classes that consist of 40 EFL students taking the Intermediate Reading and Writing course in the English Education Department in one of the large private universities in Indonesia. This study employed a causal-comparative design and lasted for twelve meetings including pretest and posttest. The two groups of HET pairs and HOM pairs experienced collaborative writing activities following the steps of the Genre-based Approach. The data were collected through writing pre-test and post-test. The data were analyzed using descriptive statistics and Mann Whitney to compare the students' post-test scores. The findings show that both high and low proficiency students who experienced collaborative writing in homogenous proficiency pairings have better writing ability than those who experienced collaborative writing in heterogeneous proficiency pairings. This indicates that pair collaboration can support language learning more optimally when there are no large proficiency gaps among pairs.
\end{abstract}

This is an open access article under the CC BY-SA license.

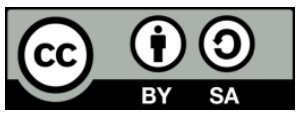

\section{Corresponding Author:}

Ani Susanti,

Graduate Program in English Language Teaching,

Universitas Negeri Malang,

Semarang No. 5 Street, Sumbersari, Lowokwari, Malang 65145, Indonesia.

Email: ani.susanti@pbi.uad.ac.id

\section{INTRODUCTION}

The use of pair work has recently been predominant in education, including in second language writing instruction. This phenomenon has probably occurred as a result of broader recognition toward an established theory in second language learning, which believes that interaction has a role in supporting learning. Sociocultural theory suggests that learning is a socially constructed activity, and interaction with others can mediate the learners' cognitive change or new understanding; through the process of interaction during pair work, knowledge is negotiated to utilize scaffolding [1, 2]. So, when the learners are working in pairs on a foreign language task, they share their language knowledge to solve their language problems.

Several studies have examined that working in pairs for collaborative writing activity could lead the learners to have more learning opportunities and to produce more accurate writing texts compared to working individually [3-7]. However, one concern the teachers might have is how to pair learners for the optimal learning outcome. Proficiency pairing is probably the most common pairing technique, especially in mixed proficiency classes. Based on the overall language proficiency, learners can be paired homogenously (High-High and Low-Low) or heterogeneously (High-Low). 
Earlier studies have documented that individuals in pairs gain more writing ability when collaborating with either equal or higher/lower partners [8-10]. However, it has become a stimulating issue because the existing studies have inconclusive outcomes, particularly about which pairing method is superior. A study on the effect of proficiency-based homogeneous and heterogeneous peer interaction on the development of the writing skills of sixty female EFL students was carried out in one of the Iranian universities [10]. The results of this quasi-experimental study showed that both groups, very similarly, had significantly higher post-test scores in all three writing tasks (Picture Description, Table Description, and Free Composition). The effect of proficiency based-heterogeneous and homogenous pairings was conducted on Saudi Arabian high school EFL students' writing achievement using a pre-test and post-test experimental design [11]. The findings suggest that there is a significant difference between the means of post-tests of the two compared groups, and homogenous pairs have been claimed to have a stronger effect than the heterogeneous pairs. Another experimental study in Nigeria concludes that in an integrated science course in Nigerian junior high school context, homogenous pairs allow students to achieve in faster learning rate to continue to progress [8].

Some other studies have found that heterogeneous pairs get better results than homogenous pairs. One of the studies examined the effect of working in homogeneous and heterogeneous pairs on students' writing skills using a quasi-experimental research design involving 40 EFL undergraduate students in Indonesia [12]. The result shows that the quality of descriptive essays produced individually by the students from the heterogeneous group was, on average, significantly better than the quality of descriptive essays produced by the students from the homogeneous group. Using a qualitative research approach, a study examines how heterogeneous grouping, particularly in writing, would impact the learning in fifth-grade elementary school students in New Jersey, USA [9]. The findings inform that heterogeneous writing groups can lead to improved writing among all students.

Since the studies, as mentioned earlier, have not shown a confident conclusion, further investigation is worth to confirm the previous studies. Therefore, the present study aims at answering whether there is any significant difference in the writing ability of the students who experience collaborative writing across proficiency pairings (heterogeneous pairs versus homogenous pairs). Furthermore, this study also aims at revealing if there is any significant difference in the writing ability of either the high and the low proficiency students who experience collaborative writing across proficiency pairings (heterogeneous pairs versus homogenous pairs).

\section{RESEARCH METHOD}

This study was conducted in the English Education Department, Universitas Ahmad Dahlan, Yogyakarta, Indonesia, one of the leading universities in Yogyakarta province, Indonesia. This study involved two intact classes of Advanced Reading and Writing course in the academic year of 2018/2019 with 20 fourth-semester students in each class. The students attend this course in two meetings a week. Each meeting lasted for 100 minutes, where one meeting concerns with reading tasks, and the other meeting concentrates on writing tasks. The tasks for the reading and the writing are interrelated regarding the topics, text types, or/and vocabularies. Based on the course description in the course syllabus, this course aims at providing experience for the students to read and write several text types that include expository writing. The two intact classed named HET Class and HOM Class.

This study compares two types of proficiency pairing and sees which one is more effective than the other; therefore, it is considered as a causal-comparative study [13, 14]. Students were paired based on their proficiency (Figure 1), as shown in their TOEFL-like score, recorded in the faculty language laboratory. Students whose score was equal to or more than 440 were considered HIGH English proficiency students, and those whose score was less than 440 were considered LOW English proficiency students. In HOM Class, the students were paired HIGH-HIGH and LOW-LOW, while in HET Class, the students were paired HIGH-LOW.

The two types of proficiency pairings were compared to examine whether the treatment given affects the students' writing ability. Pre-test and post-test were employed to measure the students' writing ability before and after the treatment. The test required the students to write an essay by selecting one of two alternative topics. Topics for pre-test were Foreign Language Learning and Ways of Getting Fit, while the topics for the post-test were The Role of Regular Exercise and Teenagers' Online Habit. The students had to read four topic-related-short-texts before they started to write the 300-400-word length essays within 90 minutes. 


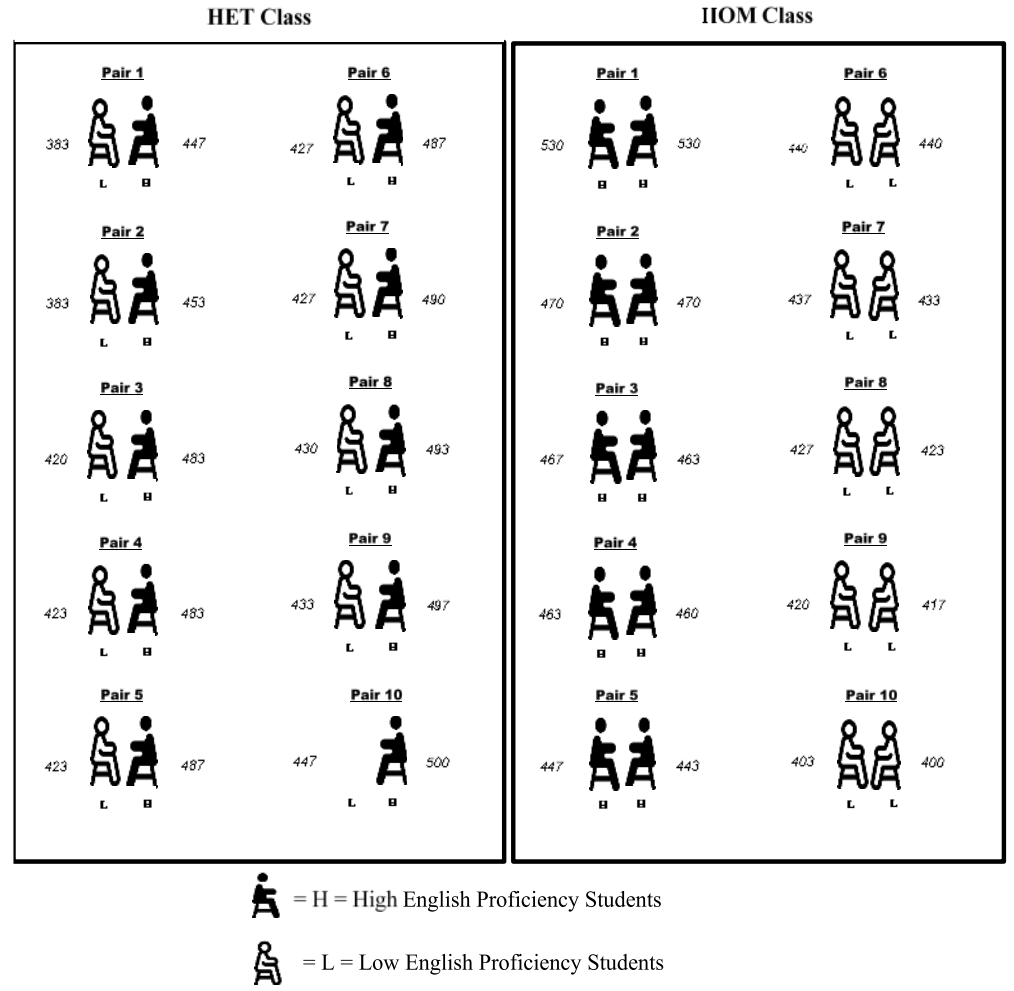

Figure 1. Proficiency pairings in HET class and HOM class

This study was conducted in 6 weeks with 12 meetings, including the sessions for pre-test and posttest (Table 1). Traning on pairing skills were given to the students to expose the students with collaborative writing strategies [15]. During the treatment, the students were assigned to write three opinion essays, by drafting the essay together with their pair. To facilitate more active interaction, the students were allowed to use L1 [16, 17].

The teaching and learning process in Advanced Reading and Writing course in Universitas Ahmad Dahlan uses Genre-Based Approach (GBA) (Figure 2). There are three main steps in the teaching and learning cycle, Modelling, Joint Construction, and Independent Construction of Text [18] as shown in Figure 2. In this course, the Modelling stage exposes the students with some reading passages as a source of ideas for writing and as a sample of the target text. The passages in the Modelling stage were varied (in the genre) to help the students identify the target text. The Joint Construction was conducted in the form of pair collaborative writing (which was the focus of the present study). The role of the teacher in this stage is as a prompt provider and a lesson organizer. In the third stage, Independent Construction of the Text, the students developed a text individually, and the teacher provided focused feedback classically to the whole students in both classes. The focus of feedback was based on the essay scoring rubric. Focused feedback is pedagogically more effective since it helps learners to pay more attention on the focused aspect [19-21]. To control the students' participation, the students were encouraged to attend regularly and get involved in every stage of the research procedure. When the students did not attend the class during the treatment, the teacher gave them a summary and an equal task. In addition, the teacher refreshed the previous materials before starting the tasks.

From the pre-test and post-test, two sets of scores (40 essays from pre-test, and 40 essays from posttest) were obtained. The essays were rated by two raters who have at least ten-year of experience in teaching English writing for university students. The involvement of two raters was to avoid bias and to increase reliability. Therefore, to help the raters to be more familiar with the rubric, they were trained before they started to use the rubric. The rubric includes six aspects that were grouped into four categories, namely content, writing purpose, organization and structure, and grammar and mechanics. It was adopted from a case study [22]. The rubric was used in this study because it is suitable for the writing task used in this study and it had been tested. After the essays were rated, the scores were analyzed using independent sample tests to see the significant difference between the two groups. The statistical analysis was conducted by using SPSS software. 
Table 1. Schedule for the treatment

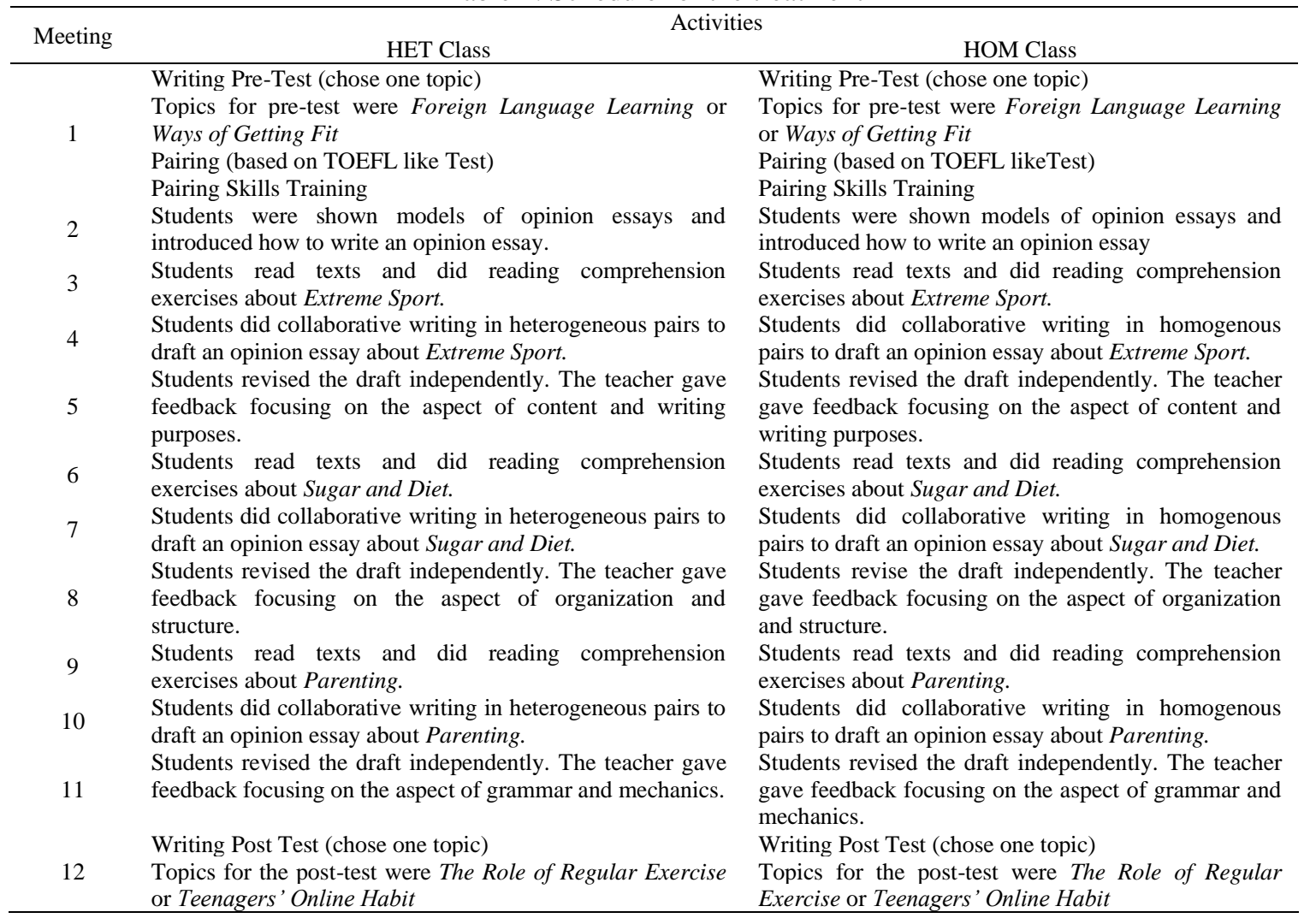

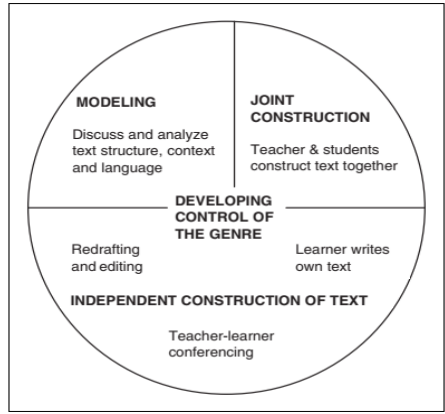

Figure 2. Teaching and learning cycle in GBA [18]

\section{RESULTS AND DISCUSSION}

Table 2 shows that the mean of the pre-test of HET class was 64.25 , with a standard deviation of 8.30 and the mean of HOM class was 61.80 , with a standard deviation of 10.21 . These scores indicate that both classes were relatively identical in terms of students' writing ability.

Table 2. Descriptive statistics of the pre-test score of HET and HOM class

\begin{tabular}{llllll}
\hline & $\mathrm{N}$ & Minimum & Maximum & Mean & Std. Deviation \\
\hline HetPre & 20 & 50.00 & 81.00 & 64.2500 & 8.30900 \\
HomPre & 20 & 44.00 & 78.00 & 61.8000 & 10.21145 \\
\hline
\end{tabular}

The pretest scores of the two intact groups (HET and HOM) were then analyzed by utilizing Levene test to know the homogeneity of the two groups. The test result demonstrated that the significance level was $.357(>0.05)$; it means that students in both groups were homogeneous in terms of their writing ability (Table 3). 
Table 3. Test of homogeneity of variances

\begin{tabular}{cccc}
\hline Levene Statistic & df1 & df2 & Sig. \\
\hline .871 & 1 & 38 & .357 \\
\hline
\end{tabular}

The means of the post-test in both HET and HOM classes improved. The mean of students' writing post-test in HET class was 69.30, with a standard deviation of 9.69. Meanwhile, the mean of students' writing post-test in HOM class was 73.25, with a standard deviation of 9.84. Figure 3 portrays the improvement in both classes, as shown from the mean scores of the pre-test and post-test.

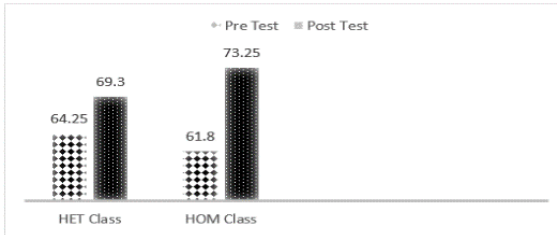

Figure 3. Pretest and posttest mean comparison

The researchers used Mann Whitney to know the significant difference in students' writing ability. Table 4 shows that the independent sample test result was .127. This result was more than (>) level of significance $(\alpha=5 \%)$. Therefore it could be concluded that there was no significant difference between students' writing ability in HET and HOM classes after they experienced pair collaborative writing.

Table 4. Descriptive statistics and mann whitney test result of means of posttests in HET and HOM classes

\begin{tabular}{lccccccc}
\hline & $\mathrm{N}$ & Min & Max & Mean & SD & Mann-Whitney & Asymp. Sig. (2-tailed) \\
\hline HET Post & 20 & 56.00 & 81.00 & 69.3000 & 9.69590 & \multirow{2}{*}{1.524} & .127 \\
HOM Post & 20 & 56.00 & 84.00 & 73.2500 & 9.84017 & & \\
\hline
\end{tabular}

The same statistical analysis was further employed to see the significant difference in high and low proficiency students' writing ability. The mean of high proficiency students' writing ability in HET class was 78.30, with a standard deviation of 3.30. Meanwhile, the mean of student's writing ability in HOM class was 81.60 , with a standard deviation of 3.40. Table 5 shows that the test result was .032 . This result was less than $(<)$ level of significance $(\alpha=5 \%)$. Therefore, it could be concluded that there was a significant difference between high proficiency students' writing ability in HET and HOM classes after experiencing pair collaborative writing.

Table 5. Descriptive statistics and mann whitney test result of means

of posttests of high proficiency students in HET and HOM classes

\begin{tabular}{llllllll}
\hline & $\mathrm{N}$ & Min & Max & Mean & SD & Mann-Whitney & Asymp. Sig. (2-tailed) \\
\hline HHET Post & 10 & 72.00 & 81.00 & 78.3000 & 3.30151 & \multirow{2}{*}{2.148} & .032 \\
HHOM Post & 10 & 75.00 & 84.00 & 81.6000 & 3.40588 & -148 & \\
\hline
\end{tabular}

The mean of low proficiency students' writing ability in HET class was 60.6, with a standard deviation of 2.75. Meanwhile, the mean of student's writing ability in HOM class was 64.90, with a standard deviation of 6.15. Table 6 shows that the test result was .038 . This result was less than $(<)$ the level of significance $(\alpha=5 \%)$. Therefore it could be concluded that there was a significant difference between low proficiency students' writing ability in HET and HOM classes after they experienced pair collaborative writing.

Table 6. Descriptive statistics and mann whitney test result of means of posttests of low proficiency students in HET and HOM classes

\begin{tabular}{lccccccc}
\hline & $\mathrm{N}$ & Min & Max & Mean & SD & Mann-Whitney & Asymp. Sig. (2-tailed) \\
\hline LHET Post & 10 & 56.00 & 66.00 & 60.6000 & 2.75681 & -2.071 & .038 \\
LHOM Post & 10 & 56.00 & 72.00 & 64.9000 & 6.15449 & -27 & \\
\hline
\end{tabular}

The descriptive statistics indicated that the students in HET and HOM classes had better writing ability after they experienced to either heterogeneous or homogenous pair collaborative writing. This is in 
line with previous findings on the impact of collaborative writing tasks on individuals' writing ability [23-27]. This finding strengthens Vygotsky's theory of Zone Proximal Development (ZPD), which believes in the role of interaction for language learning [28]. Involved in collaborative writing tasks, students who worked in heterogeneous or homogenous pairs improved their overall writing ability.

The findings of this study show that students in the HOM class gain a higher mean score compared to those in HET class, even though the statistical difference was not significant. This finding reinforces the earlier studies $[8,11]$ but it is contradictory to the other studies $[9,12,29]$. This contradiction might be affected by several factors, such as different writing tasks and conditions [30], perception and attitude [31], and task complexity [6,32]. In this research, the students were assigned to read several texts before they started writing opinion essays. The availability of the reading texts in such Genre-based Approach helped both high and low proficiency students to plan better writing as they have been exposed with stimulating information. Besides, focused feedback provided in every feedback session helped the students to pay more attention on the focused aspect.

Further, this study explored which proficiency groups of students have significantly better writing after experiencing proficiency pairings in collaborative writing tasks. It provides empirical evidence that high proficiency students who experience working in homogenous pairs have significantly better writing ability than those who experience working in heterogeneous pairs. Similar findings are also evident for low proficiency students. These findings indicate that students might learn more comfortably with relatively equal proficiency peers. This study is conducted in a country which is more hierarchical [33]. In hierarchy culture, the lower tends to take direction from those above, respect them and do not challenge opinions of those who are in higher position [34]. In this research context, when working in homogenous pairing, students might feel more equal to the other students in the pairs so they probably become more comfortable and less embarrassed to have mutual interaction. It is note worthy that good collaboration has two main principles, equality and mutuality $[35,36]$.

The findings of this study also indicate that both homogenous and heterogeneous pairs scaffold effectively as reflected in their post-test gain. However, the overall findings highlight that homogenous pairings get more benefit than heterogeneous pairings. Based on the Vygotskian perspective, more competent learners scaffold less competent ones and facilitate their progress [37]. This perspective does not directly attribute competent learners as high proficiency learners and less competent as low proficiency learners. If the gap between the pairs is too large, learning may not occur. Since ZPD is the gap between what learners can do by themselves and what they can do with other assistance [27], it is probably the case when heterogeneous pairs got less benefits as their proficiency gaps was more than 50 points.

\section{CONCLUSION}

This study provides evidence that students who experienced collaborative writing in homogenous proficiency pairings have better writing ability than those who experienced collaborative writing in heterogeneous proficiency pairings. This indicates that interaction can facilitate language learning more optimally when there are no large gaps among peers. These findings inform EFL teachers of mixed classes to be aware of the effect of proficiency pairings on students' writing ability. Even though students' participation was controlled through instructional actions and the findings of this study shows homogenous pairings give more effect on students' writing ability, this conclusion should be seen with caution since this research involves relatively small number of respondents. This study did not see closely the interaction process during the collaborative writing tasks. It is worthwhile for other researchers to conduct similar research involving more respondents and including investigation of the collaboration process. Future research may also explore more detail the dynamics of homogenous and heterogeneous pairing interaction during collaborative writing tasks so that additional in-depth explanation can be added to this conclusion.

\section{REFERENCES}

[1] J. P. Lantolf and M. E. Poehner, "Sociocultural Theory," The Encyclopedia of Applied Linguistics. Blackwell Publishing Ltd., 2013.

[2] L. S. Vygotsky, Mind in Society: The Development of Higher Psychological Processes. London, England: Harvard University Press, 1978.

[3] A. F. Dabao, "Collaborative writing tasks in the L2 classroom : Comparing group, pair, and individual work," $J$. Second Lang. Writ., vol. 21, no. 1, pp. 40-58, 2012.

[4] K. McDonough, J. De Vleeschauwer, and W. Crawford, "Comparing the quality of collaborative writing, collaborative prewriting, and individual texts in a Thai EFL context," System, vol. 74, no. 3, pp. 109-120, 2018.

[5] G. Wigglesworth and N. Storch, "Pair versus individual writing: Effects on fluency, complexity and accuracy," Lang. Test., vol. 26, no. 3, pp. 445-466, 2009. 
[6] S. Kang and J.-H. Lee, "Are two heads always better than one ? The e ff ects of collaborative planning on L2 writing in relation to task complexity," J. Second Lang. Writ., vol. 45, no. 1-2, pp. 61-72, 2019.

[7] K. McDonough, J. De Vleeschaywer, and W. J. Crawford, "Exploring the benefits of collaborative prewriting in a Thai EFL context," Lang. Teach. Res., vol. 23, no. 6, pp. 685-701, 2019.

[8] S. O. Adodo and J. O. Agbayewa, "Effect of homogenous and heterogeneous ability grouping class teaching on student's interest, attitude and achievement in integrated science," Int. J. Psychol. Couns., vol. 3, no. 3, pp. 48-54, 2011.

[9] J. L. Cady, "The Effects of Implementing Heterogeneous Writing Groups in a Fifth Grade Classroom," Unpublished thesis. Rowan University, New Jersey., 2011.

[10] P. Maftoon and N. Ghafoori, F, “A comparative study of the effect of homogeneous and heterogeneous collaborative interaction on the development of EFL learners' writing skill," J. Appl. Linguist., vol. 2, no. 1, pp. 127-158, 2009.

[11] I. A. E. M. Mahmoud, "The Effect of Homogeneous Grouping versus Heterogeneous Grouping on High School Students' EFL Writing Achievement," Unpublished Thesis. United Arab Emirates University, 2011.

[12] H. Fauziah and M. Latief, "The effect of working in heterogeneous and homogeneous pairs on the students' writing skill," Arab World English J., vol. 6, no. 2, pp. 174-188, 2016.

[13] D. Ary, L. C. Jabobs, C. Sorensen, and A. Razavieh, Introduction to Research in Education, 8th ed. Canada, USA: Cengage Learning, 2010.

[14] J. W. Creswell, Educational Research : planning, conducting and evaluating quantitative and qualitative research, 4th ed. Boston, MA: Pearson Education, 2012.

[15] M. A. Alwaleedi, R. M. Gillies, and M. O. Hamid, "Collaborative writing in Arabic as a second language ( ASL ) classrooms: A mixed-method study classrooms: A mixed-method study," Lang. Cult. Curric., vol. 32, no. 2, pp. 157-172, 2019.

[16] M. Zhang, "Collaborative writing in the EFL classroom: The effects of L1 and L2 use," System, vol. 76, no. 5, pp. 1-12, 2018.

[17] M. Zhang, "Understanding L1 and L2 interaction in collaborative writing: A lexico-grammatical analysis," Lang. Teach. Res., vol. July, pp. 1-22, 2019.

[18] K. Hyland, Second Language Writing. London, England: Cambridge University Press, 2003.

[19] F. Farrokhi and S. Sattarpour, "The Effects of Focused and Unfocused Written Corrective Feedback on Grammatical Accuracy of Iranian EFL Learners," Theory Pract. Lang. Stud., vol. 1, no. 12, pp. 1797-1803, 2011.

[20] S. M. Araghi and F. Sahebkheir, "The effect of focused versus unfocused corrective feedback on developing grammatical accuracy of Iranian EFL Learners' Written Performance within Different Gender Groups," Indian J. Fundam. Appl. Life Sci., vol. 4, no. S3, pp. 720-729, 2014.

[21] N. Shintani, R. Ellis, and W. Suzuki, "Effects of written feedback and revision on learners' accuracy in using two English," Lang. Learn., vol. 64, no. 1, pp. 103-131, 2014.

[22] S. Chan, C. Inoue, and L. Taylor, "Developing rubrics to assess the reading-into-writing skills: A case study," Assess. Writ., vol. 26, pp. 20-37, 2015.

[23] A. Shehadeh, "Effects and student perceptions of collaborative writing in L2," J. Second Lang. Writ., vol. 20, no. 4, pp. 286-305, 2011.

[24] H. Nassaji and J. Tian, "Collaborative and individual output tasks and their effects on learning English phrasal verbs," Lang. Teach. Res., vol. 14, no. 4, pp. 397-419, 2010.

[25] M. Khatib and H. Meihami, "Languaging and Writing Skill: The Effect of Collaborative Writing on EFL Students' Writing Performance," Adv. Lang. Lit. Stud., 2015.

[26] P. Ajideh, G. Leitner, and S. Y. Yazdi-Amirkhiz, "The influence of collaboration on individual writing quality: The case of Iranian vs. Malaysian college students,” vol. 17, no. 17, pp. 1-24, 2016.

[27] M. Zamani, "Cooperative learning: Homogeneous and heterogeneous grouping of Iranian EFL learners in a writing context," Cogent Educ., vol. 3, pp. 1-11, 2016.

[28] M. Saville-Troike, Introducing Second Language Acquisition. New York, USA: Cambridge University Press, 2006.

[29] Z. Wang, "Effects of Heterogeneous and Homogeneous Grouping on Student Learning," Unpublished Thesis, University of North Carolina, 2013.

[30] K. McDonough and C. G. Fuentes, "The effect of writing task and task conditions on Colombian EFL learners , language use," TESL Canada J., vol. 32, no. 2, pp. 67-79, 2015.

[31] W. Chen and S. Yu, "A longitudinal case study of changes in students' attitudes, participation, and learning in collaborative writing," System, vol. 82, pp. 83-96, 2019.

[32] Y. Kim, "The effects of task complexity on learner - learner interaction," System, vol. 37, no. 2, pp. 254-268, 2009.

[33] C. Y. Raymond and T. Choon, "Understanding asian students learning styles , cultural influence and learning strategies," J. Educ. Soc. Policy, vol. 7, no. 1, pp. 194-210, 2017.

[34] B. Peterson, Cultural Intelligence: A Guid to Working with People from Other Cultures. Maine, USA: Intercultural Press, 2004.

[35] N. Storch, "Collaborative writing: Product, process , and students ' reflections," J. Second Lang. Writ., vol. 14, no. 3, pp. 153-173, 2005.

[36] N. Storch and A. Aldosari, "Pairing learners in pair work activity," Lang. Teach. Res., vol. 17, no. 1, pp. 31-48, 2013.

[37] J. Mynard and I. Almarzouqi, "Investigating peer tutoring," ELT J., vol. 60, pp. 13-22, 2006. 